\title{
Paraphenylene Diamine (Hair Dye) Poisoning Leading to Critical Illness Neuropathy
}

Neelam Saleem Punjani*

Aga Khan University School of Nursing and Midwifery, Pakistan

\begin{abstract}
Hair dye poisoning has been evolving as one of the significant causes of intentional self-harm in the developing world. Hair dyes contain Paraphenylene-Diamine (PPD) and a host of other chemicals that can cause laryngeal edema, severe metabolic acidosis, rhabdomyolysis and acute renal failure. We present the case of a young woman who presented with complaints of progressive upper and lower limb weakness following PPD poisoning. The patient was diagnosed with the critical illness neuropathy on EMG and by history and examination. The patient was treated symptomatically and did well. Awareness and knowledge of this disorder and intervention at the right time is essential for physicians, nurses and health care workers to ensure appropriate care and treatment of such cases.
\end{abstract}

Keywords: Paraphenylenediamine poisoning; Hair dye ingestion; Critical illness neuropathy

\section{Introduction}

Paraphenylenediamine (PPD) is globally and particularly in developing countries is emerging as a common means of intentional self-harm [1]. PPD is a derivative of paranitroanaline which is extensively used as an oxidisable hair dye [2-4] (Figure 1). In Africa, Middle East and Indian subcontinent, it is mixed with the leaves of lawsonia alba (heena) which is traditionally applied to do color on hands, feet and to dye hair which gives a dark red shade [5-7].

In susceptible individuals PPD usually can cause contact dermatitis [8]. However, the major systemic problem occurs when it is ingested accidentally, for purposes of suicidal intent or during attempted murder. If ingested can cause angioedema of neck and face, acute renal failure, and rhabdomyoloses [9]. A case report is presented of a suicidal attempt following ingestion of a hair dye. However, no such study has been reported in literature on critical illness neuropathy following PPD poisoning.

\section{Case Report}

28 years old female, resident of Nawab shah presented in emergency room with complaint of progressive lower and upper limb weakness. Patient is known case of paraphenylenediamine poisoning (Black Stone) around two months back, taken to nearby hospital. She developed acute kidney injury, underwent hemodialysis (14 sessions), rhabdomylosis,

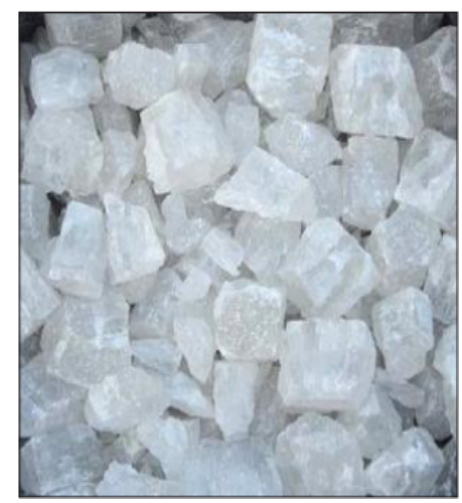

Figure 1: Paraphenylenediamine crystals. and anaphylactic shock followed by generalized body edema. She was kept in intensive care unit for a month where she developed severe SEPSIS and was on nondepolarizing neuromuscular blocking agents and ventilator support. For airway protection tracheostomy was done and closure was performed after 3 weeks. As a result of sepsis, she is than presented with progressive worsening of lower limb weakness followed by upper limb weakness for 20-25 days. She has no bladder or bowel symptoms and there is no history of trauma.

On examination she was obese lady with puffy face. Patient was vitally unstable, heart rate $133 / \mathrm{min}$, blood pressure $92 / 44 \mathrm{mmHg}$, respiratory rate $35 / \mathrm{min}$, and temperature $38.8^{\circ} \mathrm{C}$ On motor system assessment of her upper and lower limbs the bulk was reduced, tone was normal, power $3 / 5$ in upper limb whereas, $1 / 5$ in lower limbs. Reflexes were diminished in upper and lower limbs as shown in Table 1. Sensory system was intact. Her diagnostic test showed decreased haemoglobin that is $8.5 \mathrm{gm} / \mathrm{dL}(12.1-15.1 \mathrm{gm} / \mathrm{dL})$, decreased potassium that is 3.2 $\mathrm{mEq} / \mathrm{L}(3.5-5.2 \mathrm{mEq} / \mathrm{L})$, raised creatinine that is $1.9 \mathrm{mg} / \mathrm{dl}(0.5-1.4$ $\mathrm{mg} / \mathrm{dl})$, raised WBC that is $15.6\left(4.0-10.0 \times 10^{9} / \mathrm{L}\right)$, and less Vitamin D that is $6.16 \mathrm{ng} / \mathrm{mL}(20-100 \mathrm{ng} / \mathrm{mL})$. Her chest radiograph was normal. EMG was done which showed low compound muscle action suggestive of critical illness neuropathy. Patient was treated symptomatically to alleviate suffering and to promote comfort. She responded well to symptomatic treatment. She attended regular physiotherapy sessions and follow-up and has had no relapsing signs or symptoms for approximately 4 months.

\section{Discussion}

Paraphenylene diamine (PPD) is derivative of a coal-tar, which on oxidation produces Bondrowski's base, which is allergenic, mutagenic and highly toxic [1]. PPD poisoning presents with the sign and symptoms of severe angioneurotic edema, rhabdomyolysis and

*Corresponding author: Neelam Saleem Punjani, Aga Khan University School of Nursing and Midwifery, Pakistan, Tel: 9223322042134 ; E-mail: neelam.punjani@gmail.com

Received July 29, 2014; Accepted August 31, 2014; Published September 02, 2014

Citation: Punjani NS (2014) Paraphenylene Diamine (Hair Dye) Poisoning Leading to Critical IIIness Neuropathy. J Neurol Disord 2: 180. doi:10.4172/23296895.1000180

Copyright: (c) 2014 Punjani NS. This is an open-access article distributed under the terms of the Creative Commons Attribution License, which permits unrestricted use, distribution, and reproduction in any medium, provided the original author and source are credited. 
Citation: Punjani NS (2014) Paraphenylene Diamine (Hair Dye) Poisoning Leading to Critical Illness Neuropathy. J Neurol Disord 2: 180. doi:10.4172/2329-6895.1000180

Page 2 of 2

\begin{tabular}{|l|c|c|c|c|}
\hline & \multicolumn{2}{|c|}{ Upper Limb } & \multicolumn{2}{c|}{ Lower Limb } \\
\hline & Right & Left & Right & Left \\
\hline Bulk & Reduced & Reduced & Distally & Distally \\
\hline Tone & Normal & Normal & Normal & Normal \\
\hline Power & $3 / 5$ & $3 / 5$ & $1 / 5$ & $1 / 5$ \\
\hline Reflexes & Diminished & Diminished & Diminished & Diminished \\
\hline Planter & N/A & N/A & Reduced & Reduced \\
\hline
\end{tabular}

Table 1: Motor system assessment of Patient.

intravascular hemolysis with hemoglobinuria leading to acute renal failure [1,2]. PPD ingestion is common in Asia and other developing countries for intentional self-harm because of its easy availability.

PPD can cause rhabdomyolysis by promoting calcium release and leakage of calcium ions from the smooth endoplasmic reticulum, followed by continuous contraction and irreversible change in the muscle's structure [10]. Rhabdomyolysis is the main cause of acute renal failure and the morbidity and mortality are high once renal failure develops. In addition, the respiratory syndrome following the ingestion of PPD is represented by asphyxia and respiratory failure secondary to inflammatory edema involving cricopharynx and larynx [11].

The characteristic triad of features encountered are early angioneurotic edema with stridor, rhabdomyolysis with chocolate colored urine and acute renal failure [1]. Whenever this combination occurs in poisoning, hair dye is a strong suspect for diagnosis. PPD ingestion is a medical emergency. Early intervention should include gastric lavage. Patients should be monitored for respiratory distress and endotracheal intubation has to be performed early if laryngeal edema develops. Metabolic acidosis has to be corrected. Early intervention with half normal saline and soda bicarbonate infusion has been shown to be beneficial in Rhabdomyolysis.

Our patient came to emergency room after all the basic treatment. After ingestion of PPD she developed multi organ dysfunction along with the presence of SEPSIS and respiratory failure. She was on ventilator for around one month where she was kept on nondepolarizing neuromuscular blocking agents and ventilator support. After 3 weeks she had difficulty weaning from ventilator and progressive limb weakness which was suggestive of critical illness neuropathy.

Critical illness neuropathy is a disease of peripheral nerves, occurring as a complication of severe trauma or infection [12]. It is usually developed while patients are in the intensive care unit and it is typically diagnosed by limb weakness and unexplained difficulty in weaning from mechanical ventilation $[12,13]$. However, the cause of critical illness neuropathy is not known. It is commonly diagnosed by performing a thorough history and examination. Electrophysiological (needle EMG and nerve conduction studies) studies are essential for making an accurate diagnosis and excluding other causes of weakness $[12,13]$. Critical illness neuropathy tends to be more severe in those who have more severe underlying medical problems. In most patients, nerve function begins to improve once major medical issues are resolved. Our patient was treated symptomatically for one week. As symptoms starts to improve she was followed up at the outpatient department and $80 \%$ of the recovery was observed within 4 months.

\section{Conclusion}

Critical Illness Neuropathy is a rare condition that should be considered a differential diagnosis when a patient lately presents with upper and lower limb weakness after ingestion of a hair dye. It may mimic other conditions such as spinal cord dysfunction, critical illness myopathy, Guillain-Barre syndrome, motor neuron disease, porphyria, or myasthenia gravis, but history and examination plays a key role in diagnosis. Knowledge and awareness about disease among physicians, nurses and other medical professionals is essential to ensure early recognition, correct diagnosis and appropriate treatment of the problem.

\section{References}

1. Sampathkumar K, Yesudas $S$ (2009) Hair dye poisoning and the developing world. J Emerg Trauma Shock 2: 129-131.

2. Ashar A (2003) Acute angioedema in paraphenylenediamine poisoning. J Pak Med Assoc 53: 120-122.

3. Chugh KS, Malik GH, Singhal PC (1982) Acute renal failure following paraphenylene diamine [hair dye] poisoning: report of two cases. J Med 13: 131-137.

4. Ashraf W, Dawling S, Farrow LJ (1994) Systemic paraphenylenediamine (PPD) poisoning: a case report and review. Hum Exp Toxicol 13: 167-170.

5. Abdulla KA, Davidson NM (1996) A woman who collapsed after painting her soles. Lancet 348: 658.

6. Sir Hashim M, Hamza YO, Yahia B, Khogali FM, Sulieman GI (1992) Poisoning from henna dye and para-phenylenediamine mixtures in children in Khartoum. Ann Trop Paediatr 12: 3-6.

7. Yagi $\mathrm{H}$, el Hind AM, Khalil SI (1991) Acute poisoning from hair dye. East Afr Med J 68: 404-411.

8. Mathur AK, Gupta BN, Narang S, Singh S, Mathur N, et al. (1990) Biochemical and histopathological changes following dermal exposure to paraphenylene diamine in guinea pigs. J Appl Toxicol 10: 383-386.

9. Nott HW (1924) Systemic Poisoning by Hair Dye. Br Med J 1: 421-422.

10. Yabe $K$ (1992) The effect of a p-phenylenediamine containing hair dye on the $\mathrm{Ca} 2+$ mobilization in the chemically skinned skeletal muscle of the rat. Nihon Hoigaku Zasshi 46: 132-140.

11. Chugh KS, Malik GH, Singhal PC (1982) Acute renal failure following paraphenylene diamine [hair dye] poisoning: report of two cases. J Med 13: 131-137.

12. Vijayan J, Alexander M (2005) Critical illness neuropathy. Indian Journal of Critical Care Medicine 9.

13. Jani C (2011) Critical Illness Neuropathy. Medicine. 237. 